\title{
What happens
}

\section{when your}

employer loses

their contract?
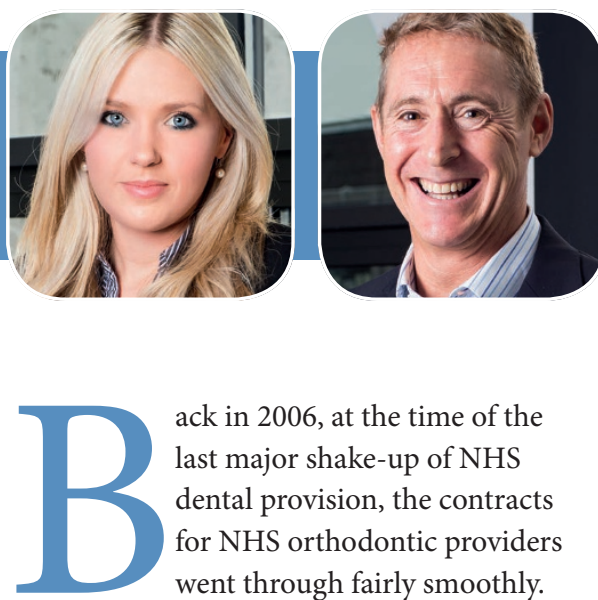

ack in 2006, at the time of the last major shake-up of NHS dental provision, the contracts for NHS orthodontic providers went through fairly smoothly. It was the GDS contracts, mostly for general dentists, which caused the headaches. Roll forward in time and it is the orthodontists who are encountering difficulties. That's because their PDS contracts, by a quirk of European law, are time limited. For some years, most primary care commissioners (Primary Care Trusts for a time) managed the situation by rolling the contracts over. But by last year, it was clear that commissioners in most parts of England were preparing to move to a new system of orthodontic commissioning. They started to invite submissions for orthodontic contracts this year with a view to new contracts rolling out in 2019. Earlier this year, the British Orthodontic Society made its concerns known, stating: 'The BOS considers that,

One of the biggest shake-ups of the last 50 years is underway in the world of orthodontics. Jasmine Sudworth and Russell Abrahams, lawyers with dental specialist law firm Abrahams Dresden, outline the implications for staff of a change in service provider.

whilst some concessions have been made by NHSE, there remains a significant risk that unintended consequences of the proposals will directly and negatively impact on patients as financial pressures start to build over the contract term.'

Nevertheless, the process is currently underway. Already there are established providers who are losing out to other bigger organisations, sometimes, but not always, tendering at a lower value than the sitting incumbent. This is not always doom and gloom for team members since TUPE - the Transfer of Undertakings (Protection of Employment) Regulations 2006 (the TUPE Regs) - are there to protect you. Nevertheless, these regulations can be confusing and as each contract transfer will be unique and it is advisable that you and/or your employer seek specific legal advice in order to establish whether the TUPE Regs apply to your individual circumstances.

Below Jasmine and Russell answer questions designed to help employees of orthodontic practices who may be unclear about their rights and their options.

\section{What is TUPE?}

The TUPE Regs apply to relevant transfers. A relevant transfer can include the situation where activities cease to be carried out by a contractor on a client's behalf and are carried out instead by another person (a subsequent contractor).

In these circumstances the client would be the NHS, the PDS contract holder would be the current contractor/ transferor and the new orthodontist under the PDS contract would be the subsequent contractor/ transferee. If there is a relevant transfer the automatic transfer principle would apply and employees will automatically transfer to the new orthodontist under the PDS contract, who will inherit all rights, liabilities and obligations in relation to the employees.

As mentioned above, each transfer will 
be unique and there are certain factors to be considered in order to establish whether the TUPE Regs apply to your individual circumstances. For instance, for there to be a relevant transfer in respect of a service provision change, the employer must have in place a team of employees who are 'essentially dedicated' to carrying out the activities that are to transfer. It could therefore be a complicating factor if the employees at your practice provide a mix of both NHS and private dental work. Similarly, whilst there is no need for the activities carried out by the new contractor to be identical, the contract transferred should relate to 'activities which are fundamentally the same as the activities carried out by the person who has ceased to carry them out'. The extent to which the new activities differ from the old will always be a matter of fact and degree. Finally, there is the possibility that if future services are to be provided by more than one contractor, the services may be considered so fragmented that there is no service provision change.

\section{When should you be told?}

The TUPE Regs require both the transferor and transferee to inform and (if appropriate) consult with recognised trade unions or elected employee representatives in relation to any affected employees.

Therefore both your employer and the new orthodontist under the PDS contract are under a duty to inform and (if appropriate) consult in relation to any of the employees who may be affected by the transfer or any measures taken in connection with it.

Please note that for smaller businesses (defined as those with fewer than 10 employees) the rules are slightly more relaxed. The TUPE Regs provide that smaller businesses may discharge their obligations to inform and consult by informing and consulting directly with the affected employees i.e. there is no need to appoint an employee representative.

In respect of timing, affected employees must be given the information required under the TUPE Regs (discussed below) 'long enough before the relevant transfer to enable the employer of any affected employees to consult the appropriate representatives of any affected employees. This is a fairly ambiguous statement. However, the Acquired Rights Directive (the framework document for the TUPE Regs) has suggested that this means within 'good time' prior to the relevant transfer. Ultimately, there is no strict time limit as to when your employer should provide you with this information and much will depend on the extent of any changes which are likely to take place as a result of the transfer.

It is important for your employer to comply with the TUPE Regs, as failure to do so exposes them to liability to pay you compensation equivalent of up to 13 weeks' pay.
This means that you could begin work under a new employment contract with your existing employer. Although, please note that this means that you will lose any rights you had accrued under your previous contract of employment.

\section{How much information should you be given?}

You have a right to be told certain information, including:

1. The fact that the transfer is going to take place, approximately when and why. All reasons should be provided where there is more than one reason for the transfer.

2. Any social, legal or economic implications, e.g. a change in location, pay, benefits, or risk of redundancies etc. If the transfer will have no such implications, then the employer should confirm as much.

3. Any measures that your employer expects to take in respect of the affected employees. If there are none then this still needs to be confirmed. Measures should be interpreted broadly to include any 'action, step or arrangement' taken in connection with the transfer.

4. Your employer must also provide information about any measures which the new orthodontist is considering taking which might affect you. Again, even if there are none this will still need to be confirmed.

\section{Can you stay on with your existing employer under a new contract of employment?}

Ultimately, yes you can. If you do not want to work for the new orthodontist, you have a right under TUPE to object to your transfer to a new employer.

If you object, your contract of employment and the rights, powers, duties and liabilities under or in connection with it will not transfer to the new orthodontist. However, you should bear in mind that your employment with the existing orthodontist is treated as terminated by operation of law with effect from the transfer date.

\section{What do I need to do to transfer to the new contract-holder?}

There is nothing for you to do in order for you to transition to the new PDS contract holder. This will happen automatically. The contracts of employment of those employees affected by the transfer automatically transfer to the new orthodontist on their existing terms from the transfer date.

\section{What happens if your employer agrees to complete the patient treatments already started?}

In relation to changes of a service provider, the transfer is regarded as taking place on the grant, assignment, surrender or termination of the relevant operating licence. That is, as soon as there is a change in the legal person responsible for running the economic unit.

Since employees transfer by operation of law the European Court of Justice has ruled that the date of the transfer is a particular point in time, which cannot be postponed to another date at the will of the transferor or transferee i.e. even if your current employer and the new orthodontist agree an alternative transfer date this will not be effective. This means that the affected employees will transfer to the new orthodontist as soon as the PDS contract is granted to them. Accordingly, your current employer cannot agree to continue to employee the transferring employees until the relevant orthodontic work has been finished and they may need to consider using agency staff and/or locums in order to fulfil this arrangement.

Of course, if you object to your transfer to the new orthodontist, you will be able to assist your employer in finishing any ongoing orthodontic treatment under your new employment contract. www.ad-solicitors.co.uk

bdjteam2018170 